\title{
Comparative study of atmospheric water vapor budget associated with precipitation in Central US and eastern Mediterranean
}

\author{
A. Zangvil ${ }^{1}$, P. J. Lamb ${ }^{2}$, D. H. Portis ${ }^{2}$, F. Jin ${ }^{1}$, and S. Malka ${ }^{1}$ \\ ${ }^{1}$ Ben Gurion University of the Negev, Beer Sheva, Israel \\ ${ }^{2}$ CIMMS, The University of Oklahoma, Norman, Oklahoma, USA
}

Received: 1 March 2009 - Revised: 12 September 2009 - Accepted: 4 January 2010 - Published: 16 February 2010

\begin{abstract}
Water vapor budget (WVB) analysis is a powerful tool for studying processes leading to precipitation $(\mathrm{P})$, since the linkages among atmospheric dynamics, water vapor fields, surface conditions, and $\mathrm{P}$ are constrained by the moisture continuity equation. This paper compares WVB calculations over the US Midwest (MW), the US Southern Great Plains (SGP), and the eastern Mediterranean Sea (EM) during their seasons of maximum P. Despite the interregional differences in time of year, size of region, and surface characteristics, the WVBs over these regions have common features. First, the change in precipitable water (dPW) is highly correlated with the moisture flux divergence (MFD) and not evaporation (E), implying that atmospheric humidity is affected more by the large-scale atmospheric circulation than land-atmosphere interactions. Second, $\mathrm{P}$ is positively correlated with moisture inflow (IF/A). However, a pronounced difference exists between the North American and the Mediterranean study regions with respect to the processes associated with increased P. For the MW and the SGP, increased $\mathrm{P}$ is associated with moisture flux convergence (-MFD) due to increased IF/A. In contrast, increased P over the EM is not associated with -MFD, since both the outflow $(\mathrm{OF} / A)$ and $\mathrm{IF} / A$ increase at similar rates.

Recycling ratio $(R)$ estimates were calculated for each region using an equation previously developed. The moisture recycling methodology involves the externally advected versus locally evaporated contributions to $\mathrm{P}$ being expressed in terms of a "bulk" formulation in which IF/A and OF/A are defined at the boundaries of the study area. Due to its scale dependence, $R$ cannot be directly compared among the
\end{abstract}

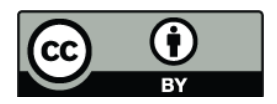

Correspondence to: A. Zangvil (zangvil@bgu.ac.il) different regions, and a normalization procedure was developed for this comparative study. Its results suggest the normalized $R$ ranges between $12-25 \%$ for the study regions, with the value for the oceanic EM being somewhat larger than over the continental MW and SGP.

\section{Introduction}

The generation of precipitation is a function of atmospheric processes and land/ocean surface characteristics, especially the degree to which they simultaneously are favorable. Many studies have addressed the large-scale circulation patterns and conditions that are conducive for generating precipitation (e.g., for the US: Lanzante and Harnack, 1982; Klein and Bloom, 1987; Peppler and Lamb, 1989; and for the Mediterranean region: Aelion, 1958; Ozsoy, 1981; Zangvil and Druian, 1990; Zangvil et al., 2003; Malka, 2006). From another perspective, the linkages among atmospheric dynamics, the atmospheric water vapor field, the land/ocean surface conditions, and precipitation are constrained by the moisture continuity equation, which contains two basic ingredients for precipitation - large-scale vertical motion and humidity. This makes water vapor budget (WVB) analysis an attractive tool for investigating the processes leading to precipitation. Many such studies have been published for diverse areas (e.g., Rasmusson, 1967, 1968; Yanai et al., 1973; Roads et al., 1994; Higgins et al., 1996; Mo and Higgins, 1996; Berbery and Rasmusson, 1999; Ruppecht and Kahl, 2003).

Early 2000 studies for WVB were published concerning Midwestern US (Zangvil et al., 2001, 2004). More recently, work was started on the WVB concerning the US Southern Great Plains as part of the "Cloud and Land Surface

Published by Copernicus Publications on behalf of the European Geosciences Union. 
Interaction Campaign" (CLASIC), under the Atmospheric Radiation Measurement (ARM) Program. ARM is a large US Global Change research program supported by the US Department of Energy. Preliminary results have been reported by Lamb et al. (2008a, b; 2009). Over the eastern Mediterranean, only a few studies have examined the water vapor field (e.g., Zangvil and Druian, 1990; Alpert and ShayEl, 1994; and Mariotti et al., 2002). Recently, Jin (2005), Malka (2006) and Jin and Zangvil (2009) performed WVB studies in relation to precipitation processes for several eastern Mediterranean regions, using reanalysis data.

The present study compares the results of WVB analyses for the above domains (Midwestern US, US Southern Great Plains, and eastern Mediterranean) concerning only their main precipitation seasons, in order to improve the understanding of precipitation generation processes. A related group of earlier studies assessed the relative contribution to regional precipitation of locally evaporated versus externally advected moisture, also termed "recycling" or the recycling ratio (e.g., Benton et al., 1950; Budyko, 1974; Brubaker et al., 1993; Burde et al., 1996; and Zangvil et al., 2004). To facilitate the inter-regional comparison, a recycling ratio normalization procedure was developed in order to account for the effects of the regions' different spatial scales. The recycling ratio normalization procedure was then applied to the study domains of the present study.

\section{Theory, data and methods}

\subsection{Moisture budget equation}

Following Yanai et al. (1973), the traditional WVB equation may be expressed in the following form:

$$
\begin{gathered}
\frac{1}{g} \frac{\partial}{\partial t} \int_{S}^{T} q d p+\frac{1}{g} \int_{S}^{T} \nabla \cdot q \boldsymbol{V} d p=\mathrm{E}-\mathrm{P} . \\
\mathrm{dPW}
\end{gathered}
$$

Where, $q$ is specific humidity, $p$ is atmospheric pressure, $\boldsymbol{V}$ is the horizontal wind vector, $g$ is the acceleration due to gravity, $S$ and $T$ indicate the land/ocean surface and an upper integration limit, respectively, $\mathrm{E}$ is the surface evaporation rate, $\mathrm{P}$ is precipitation, $\mathrm{dPW}$ is the time change of atmospheric water vapor (precipitable water, PW), and MFD is the horizontal moisture flux divergence.

By applying Green's Theorem to the MFD term in Eq. (1), Zangvil et al. (2004) obtained

$$
\begin{aligned}
& \mathrm{MFD}=\frac{1}{g} \int_{S}^{T} \nabla \cdot q \boldsymbol{V} d p=\frac{1}{A g} \int_{S}^{T} \oint q v_{\mathrm{n}} d l d p \\
& =\frac{\mathrm{OF}}{A}-\frac{\mathrm{IF}}{A}
\end{aligned}
$$

where $A$ is the area of the region, $v_{\mathrm{n}}$ is the wind component normal to the region's boundary, $d l$ is a length increment along that boundary, and $\mathrm{OF} / A$ and IF/ $A$ are the total water vapor outflow from and inflow into the region, respectively. The line integral Eq. (2) is evaluated along the region's boundary using the vertically integrated water vapor flux and yields the total regional $\mathrm{OF} / A$ and IF/A. Substituting Eq. (2) into Eq. (1) yields

$\mathrm{E}-\mathrm{P}=\frac{\mathrm{OF}}{A}-\frac{\mathrm{IF}}{A}+\mathrm{dPW}$,

which is illustrated in Fig. 1d. To quantify the advected $(\mathrm{IF} / \mathrm{A})$ and locally evaporated (E) origins of $\mathrm{P}$, Zangvil et al. $(1992,2004)$ derived the recycling formula

$R=\frac{\mathrm{P}_{\mathrm{E}}}{\mathrm{P}}=\frac{\mathrm{E}}{\mathrm{E}+\frac{\mathrm{IF}}{A}}$,

where, $\mathrm{P}_{\mathrm{E}}$ is the amount of $\mathrm{P}$ originating from local $\mathrm{E}$.

\subsection{Scale dependence of IF/ $A$ and $R$}

Although none of the water vapor budget components is explicitly scale-dependent in Eq. (1), it is highly conceivable that scale dependence characterizes the WVB. P and MFD, and to a lesser extent $\mathrm{E}$ and $\mathrm{dPW}$, are area dependent, since the $\mathrm{P}$ patterns are synoptically driven, at least in part. Generally, it was expected that the temporal variability of these components was larger/diminished in small/expanded areas. Also, there is scale dependence in $\mathrm{IF} / A, \mathrm{OF} / A$, and the derived $R$ that is explicit in $A$ and implicit in the closed line integral in Eq. (2). Since most of the study regions used in WVB research are nearly square-shaped, consider a square region with an area $A$ and side $L$. For simplicity, assume the flow to be perpendicular to one pair (zonal or meridional) of the sides of the regions and that the only contribution to the inflow comes from the up-wind side, which reduces Eq. (2) to

$\frac{1}{A g} \int_{S}^{T} \oint q v_{\mathrm{n}} d l d p=\frac{\mathrm{IF}}{A}$.

Denoting the vertically integrated moisture flux by $\overline{q v}$, Eq. (5) may be rewritten as

$\frac{1}{A g} \overline{q v} L=\frac{\mathrm{IF}}{A}$

or,

$\frac{\mathrm{IF}}{A}=\frac{\overline{q v}}{g L}$.

Thus, due to the scale dependence, it is impossible to make meaningful comparisons of IF/ $A$ and $R$ between regions of different sizes. This problem can be overcome by the normalization described next. 

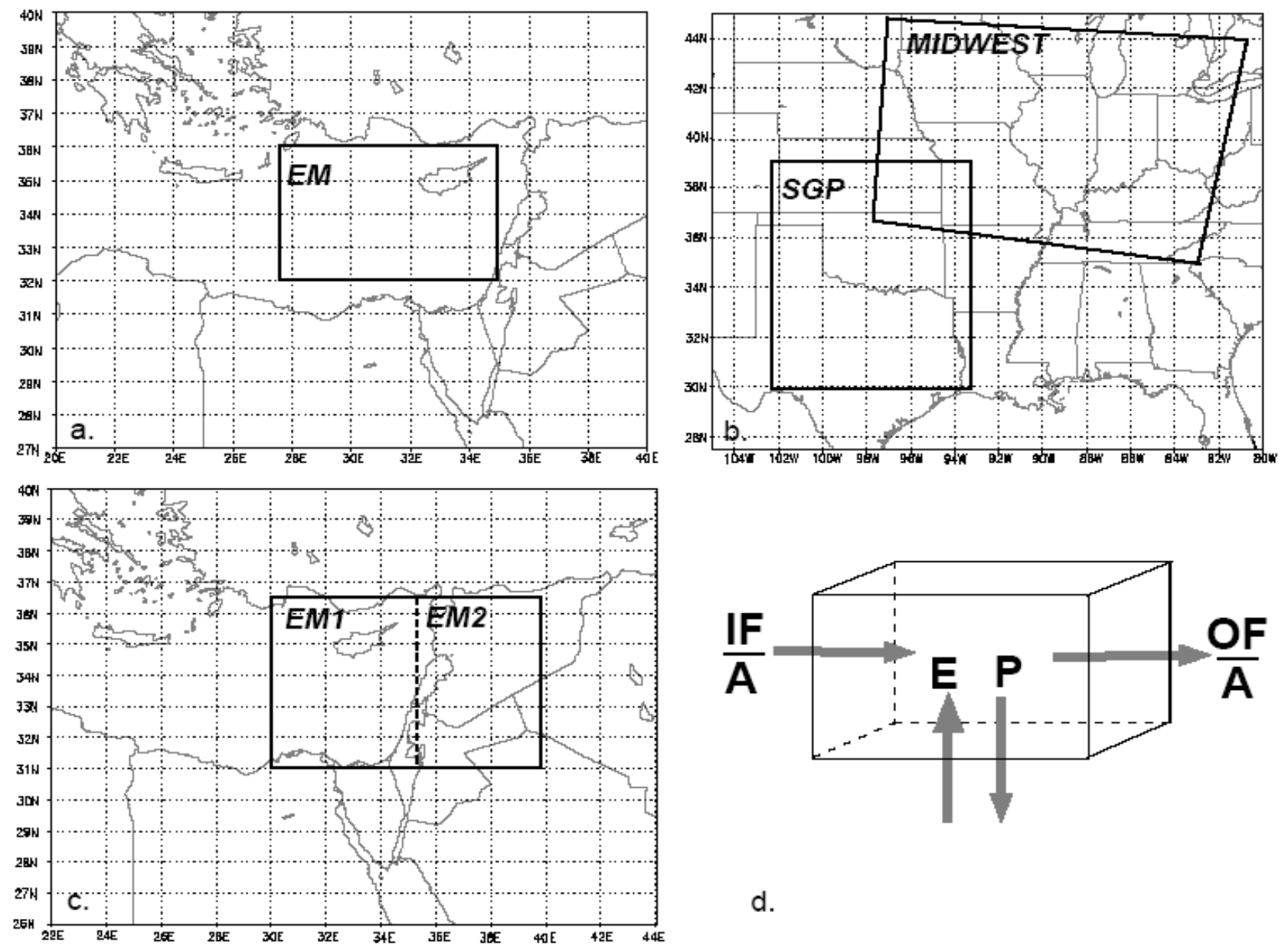

d.

Fig. 1. Orientation map. Delineated approximately rectangular regions formed the bases of atmospheric volumes illustrated in (d) for which moisture budget components were estimated. (a) Eastern Mediterranean (EM), (b) US Midwest (MW) and Southern Great Plains (SGP), (c) coastal (EM1) and inland (EM2) eastern Mediterranean regions, (d) WVB components symbols for atmospheric volume as in Eq. (3).

\subsection{Normalization of inflow (IF/A)}

Equation (6a) may be applied to any virtual square region of arbitrary side $L_{0}$ and arbitrary area $A_{0}$, to give

$$
\left(\frac{\mathrm{IF}}{A}\right)_{0}=\frac{\overline{q v}}{g L_{0}} \text {. }
$$

Finally, Eq. (6a) and Eq. (6b) are resulting in

$$
\left(\frac{\mathrm{IF}}{A}\right)_{0}=\left(\frac{\mathrm{IF}}{A}\right) \frac{L}{L_{0}}
$$

Equation (7) may be used to transform the measured vertically integrated moisture flux into region $A$ to the flux into an arbitrary area $A_{0}$. This procedure was applied to produce normalized values of the inflow values $(\mathrm{IF} / A)_{0}$ using the normalization factor $L / L_{0}$ (Table 1 ) for each of the regions used here (Fig. 1a-c) Midwestern US (MW), US Southern Great Plains (SGP), eastern Mediterranean (EM), (EM1) and (EM2). The arbitrary normalization area was chosen to be
Table 1. Area and normalization information for study regions named in Sect. 2.3 and delineated in Fig. 1. The normalization area $A_{0}$ used $\left(0.7 \times 10^{6} \mathrm{~km}^{2}\right)$ was close to the mean of the North American regions and the eastern Mediterranean regions to which it was applied. The normalization factor $L / L_{0}$ was obtained as $\sqrt{A} / \sqrt{A_{0}}$ where $A$ is the area of each region. See Sect. 2.3 for underlying theory.

\begin{tabular}{lcc}
\hline Region & Area $\left(\mathrm{km}^{2}\right)$ & $\begin{array}{c}\text { Normalization } \\
\text { Factor } L / L_{0}\end{array}$ \\
\hline MW & $1.23 \times 10^{6}$ & 1.326 \\
SGP & $0.83 \times 10^{6}$ & 1.089 \\
EM & $0.304 \times 10^{6}$ & 0.659 \\
EM1 & $0.31 \times 10^{6}$ & 0.665 \\
EM2 & $0.31 \times 10^{6}$ & 0.665 \\
\hline
\end{tabular}


Table 2. Mean WVB components and $R$ values for the MW, SGP, and EM regions delineated in Fig. 1a and b. Symbols are as in the text. $\mathrm{IF} / A$ and $R$ values are presented in original and normalized forms (see Sect. 2.3). Normalized $R$ values were computed using Eq. (4) with normalized IF/ $A$ values given by Eq. (7). Small $\mathrm{P}$ in the MW and SGP refers to $\mathrm{P} \leq 0.6 \mathrm{~mm} \mathrm{~d}^{-1}$, and large $\mathrm{P}$ there is for $4<\mathrm{P} \leq 8 \mathrm{~mm} \mathrm{~d} \mathrm{~d}^{-1}$. For the EM, these ranges are $0.01 \leq \mathrm{P} \leq 0.15$ and $0.9 \leq \mathrm{P} \leq 2.2 \mathrm{~mm} \mathrm{~d}^{-1}$, respectively. Units are $\mathrm{mm} \mathrm{d}^{-1}$, except for $\mathrm{PW}(\mathrm{mm})$ and $R(\%)$.

\begin{tabular}{lccrccrccc}
\hline $\begin{array}{l}\text { Region } \\
\text { P-Category }\end{array}$ & P & E & MFD & $\begin{array}{c}\mathrm{IF} / A \\
\text { Original }\end{array}$ & $\begin{array}{c}\mathrm{IF} / A \\
\text { Normalized }\end{array}$ & $\mathrm{dPW}$ & $\begin{array}{c}\mathrm{PW} \\
(\mathrm{mm})\end{array}$ & $\begin{array}{c}R(\%) \\
\text { Original }\end{array}$ & $\begin{array}{c}R(\%) \\
\text { Normalized }\end{array}$ \\
\hline MW (Small P) & 0.2 & 4.8 & 3.4 & 11.9 & 15.8 & 1.2 & 23.1 & 29 & 23 \\
MW (Large P) & 5.7 & 3.8 & -0.6 & 22.0 & 29.2 & -1.3 & 32.4 & 15 & 12 \\
SGP (Small P) & 0.2 & 3.5 & 1.9 & 16.0 & 17.4 & 1.2 & 29.1 & 18 & 17 \\
SGP (Large P) & 5.7 & 3.7 & -2.4 & 20.5 & 22.3 & 0.2 & 37.6 & 15 & 14 \\
EM (Small P) & 0.1 & 3.2 & 2.7 & 14.8 & 9.8 & 0.6 & 13.4 & 18 & 25 \\
EM (Large P) & 1.5 & 4.1 & 3.9 & 22.2 & 18.8 & -0.6 & 15.7 & 16 & 18 \\
\hline
\end{tabular}

$0.7 \times 10^{6} \mathrm{~km}^{2}$ which is close to the mean of the central North American and eastern Mediterranean regions.

\subsection{Data and analysis}

For the MW study (Fig. 1b), radiosonde data (from the US National Weather Service and the Canadian Atmospheric Environment Service) and raingauge measurements at 600 locations were used for the May-August periods of 1975,1976,1979, and 1988, with a combined total of 488 days (see Zangvil et al., 2001, 2004 for a description of datasets and methodology). For the SGP study (Fig. 1b), the NCEP North American Regional Reanalysis (NARR; Mesinger et al., 2006) dataset and the NCEP daily gridded precipitation analysis from the NCEP Climate Prediction Center (ftp://ftp.cpc.ncep.noaa.gov/precip/wd52ws/ us_daily/) were used for the May-June periods in 2006 and 2007, with a combined total of 120 days. For the EM (Jin and Zangvil, 2009) and EM1/EM2 (Malka, 2006) studies (Fig. 1a and c), NASA/DAO reanalysis data (including $\mathrm{P}$ and E values; see Schubert et al., 1993 for a description of the NASA/DAO reanalysis) were used for eight consecutive winters (October-April) between 1985-1993, with a combined total of 1698 days. In both North American studies, surface E was obtained as the residual of Eq. (1).

In the MW, SGP, and EM studies, the WVB components were stratified by precipitation (P) amounts. For the MW and SGP, where $P$ was not model-derived, the $P$ categories were: $\mathrm{P}<0.6 ; 0.6<\mathrm{P}<2 ; 2<\mathrm{P}<4 ; 4<\mathrm{P}<8$; and $8<\mathrm{Pmmd}^{-1}$. In the EM study, where $P$ was modelderived, the $P$ categories were: $0.01<\mathrm{P}<0.15 ; 0.15<\mathrm{P}<0.4$; $0.4<\mathrm{P}<0.9 ; 0.9<\mathrm{P}<2.2$; and $2.2<\mathrm{P} \mathrm{mm} \mathrm{d}^{-1}$. The magnitude of these modeled $P$ data was lower by a factor of $\sim 2$ than $\mathrm{P}$ estimates over the EM. All above $\mathrm{P}$ categories were chosen so that an approximately equal number of $\mathrm{P}$ days would finally belong to each category. For the study regions EM1 and EM2, auxiliary raingauge data were used to determine major rain days in Israel. A major rain day (MRD) at a given station had a P amount of at least $10 \%$ of the long-term monthly mean P at that station (Zangvil and Druian, 1990).

\section{Results and discussion}

Since previous publications contain detailed presentations and discussions of the results for the above study regions, the effort of the present study is to focus on the important inter-regional similarities and differences and their physical implications. Relations between the WVB components are identified through stratification by $\mathrm{P}$ amount, linear correlation analysis, and use of the recycling ratio $R$. Finally, a discussion of the synoptic aspects provides physical insight into the WVB differences between our study regions.

\subsection{Stratification of WVB}

Mean WVB component values for the MW, SGP, and EM regions are presented in Table 2 for "small" and "large" $\mathrm{P}$ categories. Over the MW and SGP, the MFD decreases as P increases and becomes negative (convergent) for large $P$. This is in pronounced contrast to the situation in the EM, where the positive mean MFD for small $\mathrm{P}$ increases further for large P. From Table 2 it is apparent that the original IF/ $A$ values for each $\mathrm{P}$ category are of similar magnitude in the three regions, but for the EM the normalized IF/ $A$ is considerably lower than that for North America. This result is consistent with the lower winter PW in the EM, compared to the high summer PW in North America. Another interesting finding involves the behavior of $\mathrm{dPW}$ in the three regions. For small $\mathrm{P}$ some moisture storage occurs in all regions, while for large $\mathrm{P}$ there is moisture depletion in the MW and EM and small storage for the SGP.

Table 3 gives mean values of the WVB components for the EM1 and EM2 regions associated with MRDs in Israel determined by the procedure outlined in Sect. 2.4. This P stratification essentially corresponds to the "Large P" category shown in Table 2. The WVB component for the maritime 
Table 3. Mean WVB components and $R$ values for the EM1 and EM2 regions delineated in Fig. 1c for 480 major rain days (MRDs) in Israel (defined in Sect. 2.4) during the winters of 1985-1993, based on Malka (2006). Symbols are as in the text. IF/ $A$ and $R$ values are presented in original and normalized forms (see Sect. 2.3).

\begin{tabular}{ccccccccc}
\hline Region & $\mathrm{P}$ & $\mathrm{E}$ & $\mathrm{MFD}$ & $\begin{array}{c}\mathrm{IF} / A \\
\text { Original }\end{array}$ & $\begin{array}{c}\mathrm{IF} / A \\
\text { Normalized }\end{array}$ & $\mathrm{dPW}$ & $\begin{array}{c}R(\%) \\
\text { Original }\end{array}$ & $\begin{array}{c}R(\%) \\
\text { Normalized }\end{array}$ \\
\hline EM1 & 2.4 & 4.4 & 4.4 & 25.8 & 17.2 & -0.8 & 15 & 20 \\
EM2 & 1.9 & 2.1 & 0 & 29.5 & 19.6 & -0.5 & 7 & 10 \\
\hline
\end{tabular}

Table 4. Linear correlation coefficients between WVB components for the MW, SGP, and EM regions. Using a 2-tailed t test that accounted for non-independence of the data (see Zangvil et al., 2001; Jin and Zangvil, 2009), the 95\% (99\%) confidence levels for each region are MW: 0.18 (0.23); SGP: 0.36 (0.46); EM: $0.11(0.15)$.

\begin{tabular}{lcccccc}
\hline Region & P \& MFD & P \& IF/A & P \& PW & P \& E & E \& OF/A & MFD \& dPW \\
\hline MW & -0.40 & +0.58 & +0.42 & +0.06 & +0.14 & -0.68 \\
SGP & -0.68 & +0.31 & +0.68 & +0.23 & +0.21 & -0.60 \\
EM & -0.08 & +0.45 & +0.21 & +0.36 & +0.35 & -0.61 \\
\hline
\end{tabular}

EM1 region, which partly overlaps EM, shows a behavior similar to that of the large P in the EM. In EM2, MFD drops to zero, presumably because of intensified IF/ $A$ downwind of EM1.

\subsection{Correlation between WVB components}

For the MW, SGP, and EM regions, the linear correlation coefficients were calculated between all WVB components. Table 4 presents the key correlation values obtained along with information on their statistical significance based on Zangvil et al. (2001) and Jin and Zangvil (2009). There is a striking similarity between most of the correlations for the two US regions. For both the MW and SGP, there are moderateto-strong correlations (magnitudes of 0.31 to 0.68 ) between $\mathrm{P}$ and MFD, $\mathrm{P}$ and $\mathrm{IF} / A$ and $\mathrm{P}$ and $\mathrm{dPW}$. The correlation between $\mathrm{P}$ and $\mathrm{E}$ is near zero for the MW and only +0.23 over the SGP. For the EM the correlation between P and MFD also is near zero, while larger correlations occur between $\mathrm{P}$ and $\mathrm{E}(+0.36)$ and $\mathrm{P}$ and $\mathrm{IF} / A(+0.45)$. The +0.36 correlation between $\mathrm{P}$ and $\mathrm{E}$ in the $\mathrm{EM}$ emphasizes the important role of water vapor originating in the EM for $\mathrm{P}$ in that region. Also, there are strong negative correlations between MFD and dPW in all three regions $(-0.60$ to -0.68$)$, indicating that the change in atmospheric water vapor storage is affected strongly by the large scale MFD, whereas the correlations of $\mathrm{E}$ with $\mathrm{dPW}$ are very low (not shown). Finally, there is a good correlation between $\mathrm{E}$ and $\mathrm{OF} / A$ for the EM, but not for MW and SGP (see Sect. 4).

\subsection{Recycling}

The results also shed further light on the relative importance for $\mathrm{P}$ of local $\mathrm{E}$ versus externally advected moisture. On one hand, the correlation results in Table 4 clearly emphasize the much stronger overall association of $\mathrm{P}$ with other WVB components when the datasets were analyzed in their entirety. However, this bulk approach obscures key information that emerges through the application of the above normalization (for $\mathrm{IF} / A$ and $R$ ) and stratification (by $\mathrm{P}$ ) procedures. Before the IF/ $A$ normalization, $R$ did not differ considerably between regions except for MW for small $\mathrm{P}$ (Tables 2 and 3 ). The prominent characteristic of the normalized $R$ values is the relatively large $R$ in the EM for both small and large $\mathrm{P}$ amounts compared to both the MW and SGP (Table 2). This means that locally evaporated EM sea water constitutes a significant fraction of this region's P. Note also that $R$ in EM2 is smaller by a factor of 2 than $R$ in EM1 (Table 3 ). This result is consistent with the significantly lower E over the EM2 land area.

\subsection{Synoptic controls}

From the synoptic point of view, the different behavior of the WVB components between the study regions may be explained in part by the location of maximum $\mathrm{P}$ with respect to the mid-upper tropospheric trough. In the Central US, spring and summer precipitation occur when moist southerly flow from the Gulf of Mexico prevails to the east of the surface low (see Fig. 2 based on Holton, 1972, Fig. 7.10). In contrast, in the EM2 region the southerly flow ahead of the surface low is very dry, and as a result most of the rainfall takes place near or behind the surface cold front in proximity to the upper air 


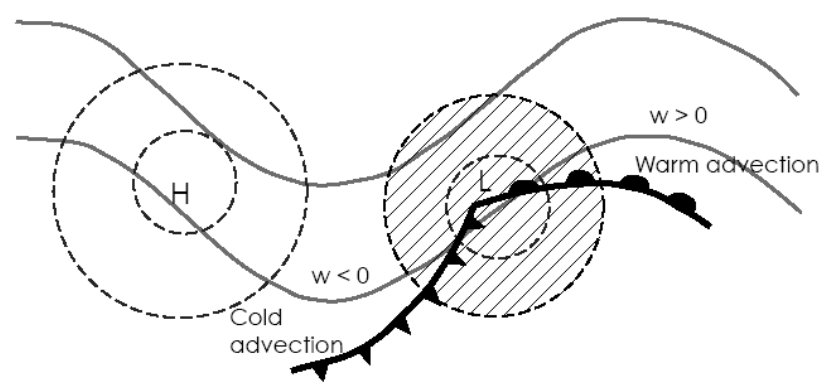

Fig. 2. Schematic presentation of a typical synoptic situation leading to precipitation in the MW and SGP. Solid lines represent $500 \mathrm{hPa}$ geopotential height and dashed lines represent surface pressure. Stippling denotes areas of precipitation and $w$ indicates vertical velocity (positive upward). Based on Fig. 7.10 in Holton (1972).

trough line (Fig. 3), as described in Aelion (1958), Zangvil et al. (2003), and Malka (2006). In the EM region, maximum $P$ occurs further west, between the upper air trough line and the surface low, known as the Cyprus Low (see Fig. 7; in Jin and Zangvil, 2009). A possible explanation for the positive MFD associated with large $\mathrm{P}$ in the EM (Tables 2 and 3), the $\mathrm{OF} / A$ from the region is larger than the $\mathrm{IF} / A$ - lies in the $\mathrm{E}$ from the eastern Mediterranean Sea. This E may contribute to an increased OF/A resulting in a positive MFD. The high correlation between $\mathrm{E}$ and $\mathrm{OF} / \mathrm{A}$ supports this interpretation (Table 4).

\section{Summary and conclusions}

Separate atmospheric water vapor budget (WVB) analyses were conducted for the: (1) Midwestern US (MW); (2) the Southern Great Plains in the south central US (SGP); and (3) the eastern Mediterranean Sea (EM) and two additional areas (EM1 and EM2), the latter being a coastal region. These analyses identified the following large-scale dynamical and WVB-related processes associated with precipitation $(\mathrm{P})$ in the study regions:

1. For the MW and SGP, the processes associated with increased $\mathrm{P}$ include a gradual decrease in moisture flux divergence (MFD), through increased moisture inflow (IF/A), reaching negative values of MFD (convergence).

2. Over the EM, increased $P$ is not related to decreased MFD, since both IF/A and moisture outflow (OF/A) increase at similar rates. However, there is an increase in $\mathrm{E}$ with $\mathrm{P}$, which supports the increased $\mathrm{OF} / \mathrm{A}$. Hence, the role of $\mathrm{E}$ as a source of moisture, or trigger, for $\mathrm{P}$ in the EM may be more important for the eastern Mediterranean Sea than in the terrestrial central US.

3. A normalization procedure was developed to allow meaningful comparison of the scale-dependent IF/A

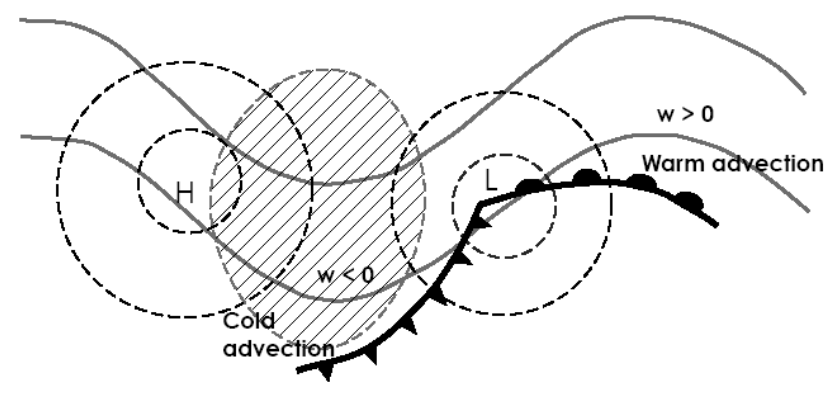

Fig. 3. Same as Fig. 2, but for the eastern Mediterranean.

and $R$ obtained in studies of different horizontal scales. Consistent with the possibility raised in 2 above, the normalized $R$ for the EM is larger than those for the MW and SGP. With movement eastwards from EM1 (sea surface) to EM2 (land), there is a drop in the normalized $R$ from $20 \%$ in the maritime region to $10 \%$, in the continental region.

4. The major atmospheric agent changing the large-scale atmospheric humidity over the MW, SGP, and EM was shown to be the MFD.

5. From the synoptic point of view, $P$ in the central US was suggested to be associated with moist southerly flow from the Gulf of Mexico advected northwards to the east of a surface low pressure system. For the arid continental EM2 region, the southerly flow ahead of the surface low is very dry, and as a result most $\mathrm{P}$ occurs near or behind the surface cold front in proximity to the upper trough line. Over the EM, the location of the rainfall is between the surface low and the mid-tropospheric upper air trough line.

Acknowledgements. This research was supported by grants from the Israeli Ministry of Science and Technology (GLOWA-Jordan River), the German Bundesministerium für Bildung und Forschung (BMBF), the Atmospheric Radiation Measurement (ARM) Program of the US Department of Energy, and the US National Science Foundation. Thanks are due to the anonymous reviewers for their helpful comments and to D. Klepach for his assistance in programming.

Edited by: S. Michaelides, K. Nicolaides, and A. Orphanou Reviewed by: two anonymous referees

\section{References}

Aelion, E.: A report on weather types causing marked storms in Israel during the cold season, Israel Meteorological Service, Miscellaneous Papers, Series C, No. 10, 7 pp. 1958.

Alpert, P. and Shay-El, Y.: The Moisture Source for the Winter Cyclones in the EM, Israel Meteorological Research Papers, 5, 20-27, 1994. 
Berbery, E. H. and Rasmusson, E. M.: Mississippi moisture budgets on regional scale, Mon. Weather Rev., 127, 2654-2673, 1999.

Benton, G. S., Blackburn, R. T., and Snead, V. O.: The role of the atmosphere in the hydrologic cycle, Eos. Trans. Amer. Geophys. Union, 31, 61-73, 1950.

Brubaker, K. L., Entekhabi, D., and Eagleson, P. S.: Estimation of continental recycling, J. Climate, 6, 1077-1089, 1993.

Budyko, M. I.: Climate and Life, Academic Press, New York, NY, USA., 508 pp., 1974.

Burde, G. I., Zangvil, A., and Lamb, P. J.: On estimating the role of local evaporation in precipitation for a two-dimensional region, J. Climate, 9, 1328-1338, 1996.

Higgins, R. W., Mo, K. C., and Schubert, S. D.: The moisture budget of the central United States in spring as evaluated in the NCEP/NCAR and the NASA/DAO reanalysis, Mon. Weather Rev., 124, 939-963, 1996.

Holton, J. R.: An Introduction to Dynamic Meteorology, Academic Press, New York, NY, USA, 319 pp., 1972.

Jin, F.: The connection between water vapor budget components and rainfall in the eastern Mediterranean, MS Thesis, Albert Katz International School for Desert Studies, Ben Gurion University of the Negev, Beer Sheva, Israel, 63 pp., 2005.

Jin, F. and Zangvil, A.: Relationship between moisture budget components over the eastern Mediterranean, Int. J. Climatol., doi:10.1002/joc,1911, in press, 2009.

Klein, W. H. and Bloom, H. J.: Specification of monthly precipitation over the United States from the surrounding $700 \mathrm{mb}$ height field, Mon. Weather Rev., 115, 2118-2132, 1987.

Lamb, P. J., Zangvil, A. and Portis, D. H.: Investigation of the Southern Great Plains Moisture Budget for CLASIC, in: Proceedings of the Eighteenth Atmospheric Radiation Measurement (ARM) Science Team Meeting, http://www.arm.gov/ publications/proceedings/conf18/display.php?id=NDgz, last access: 10 February 2010, Norfolk, VA, USA, 10-14 March, 2008a.

Lamb, P. J., Zangvil, A., and Portis, D. H.: Investigation of the Southern Great Plains Moisture Budget for CLASIC, American Geophysical Union (AGU) Fall Meeting, San Francisco, Ca, USA, 5-19 December, 2008b.

Lamb, P. J., Zangvil, A., and Portis, D. H.: Investigation of the Southern Great Plains Moisture Budget for CLASIC, in: Proceedings of the Nineteenth Atmospheric Radiation Measurement (ARM) Science Team Meeting, http://www.arm.gov/ publications/proceedings/conf19/display.php?id=NjE3, last access: 10 February 2010, Louisville, Ky, USA, 30 March-4 April, 2009

Lanzante, J. R. and Harnack, R. P.: Specification of United states summer season precipitation, Mon. Weather Rev., 110, 18431850, 1982.

Malka, S.: Analysis of the water vapor field and synoptic characteristics in relation to temporal and regional variation of precipitation in Israel, M. S. Thesis, Albert Katz International School for Desert Studies, Ben Gurion University of the Negev, Beer Sheva, Israel, 99 pp., 2006.

Mariotti, A., Struglia, M. V., Zeng, N., and Lau, K. M.: The hydrological cycle in the Mediterranean region and implications for the water budget of the Mediterranean Sea, J. Climate, 15, 16741690, 2002.
Mesinger, F., DiMego, G., Kalnay, E., Mitchell, K., Shafran, P. C., Ebisuzaki, W., Jovic, D., Woollen, J., Rogers, E., Berbery, E. H., Ek, M. B., Fan, Y., Grumbine, R., Higgins, W., Li, H., Lin, Y., Manikin, G., Parrish, D., and Shi, W.: North American Regional Reanalysis, B. Am. Meteor. Soc., 87, 343-360, 2006.

Mo, K. C. and Higgins, R. W.: Large-scale atmospheric moisture transport as evaluated in the NCEP/NCAR and NASA/DAO reanalysis, J. Climate, 9, 1531-1545, 1996.

Ozsoy, E.: On the Atmospheric Factors Affecting the Levantine Sea, European Center for Medium Range Weather Forecasts, Technical Report No. 25, Shinfield Park, Reading, UK, 29 pp., 1981.

Peppler, R. A. and Lamb, P. J.: Tropospheric static stability and central North American growing season rainfall, Mon. Weather Rev., 117, 1156-1180, 1989.

Rasmusson, E. M.: Atmospheric water vapor transport and the water balance of North America, Part I: Characteristics of the water vapor flux field, Mon. Weather Rev., 95, 403-426, 1967.

Rasmusson, E. M.: Atmospheric water vapor transport and the water balance of North America, Part II: Large-scale water balance investigations, Mon. Weather Rev., 96, 720-734, 1968.

Roads, J. O., Chen, S. C., Guetter, A. K., and Georgakakos, K. P.: Large-scale aspects of the United States hydrologic cycle, B Am. Meteor. Soc., 75, 1589-1610, 1994.

Ruppecht, E. and Kahl, T.: Investigation of the atmospheric water budget of the BALTEX area using NCEP/NCAR reanalysis data, Tellus A, 55, 426-437, 2003.

Schubert, S. D., Rood, R. B., and Pfaendtner, J.: An assimilated dataset for earth science applications, B. Am. Meteor. Soc., 74, 2331-2342, 1993.

Yanai, M., Esbensen, S., and Chu, J. H.: Determination of average bulk properties of tropical cloud clusters from large-scale heat and moisture budgets, J. Atmos. Sci., 30, 611-627, 1973.

Zangvil, A. and Druian, P.: Upper air trough axis orientation and the spatial distribution of rainfall over Israel, Int. J. Climatol., 10, 57-62, 1990.

Zangvil, A., Portis, D. H., and Lamb, P. J.: Interannual variation of the moisture budget over the Midwestern United States in relation to summer precipitation, Part II: Impact of local evaporation on precipitation, in: Proceedings of the Yale Mintz Memorial Symposium on Climate and Climate Change, Jerusalem, Israel, 28-31 December 1992, 101, 1992.

Zangvil, A., Karas, S., and Sasson, A.: Connection between eastern Mediterranean seasonal mean $500 \mathrm{hPa}$ height and sea-level pressure patterns and the spatial rainfall distribution over Israel, Int. J. Climatol., 23, 1567-1576, 2003.

Zangvil, A., Portis, D. H. and Lamb, P. J.: Investigation of the largescale atmospheric moisture field over the Midwestern United States in relation to summer precipitation, Part I: Relationships between moisture budget components on different timescales, J. Climate, 14, 582-597, 2001.

Zangvil, A., Portis, D. H., and Lamb, P. J.: Investigation of the large-scale moisture field over the Midwestern United States in relation to summer precipitation, Part 2: Recycling of local evapotranspiration and association with soil moisture and crop yields, J. Climate, 17, 3283-3301, 2004. 